\title{
Optimization of injection pressure for a compression ignition engine with cotton seed oil as an alternate fuel
}

\author{
S. Naga Sarada ${ }^{1}$, M.Shailaja ${ }^{2}$, A.V. Sita Rama Raju ${ }^{1}$, K. Kalyani Radha ${ }^{3 *}$ \\ ${ }^{1}$ Department of Mechanical Engineering, JNTUH College of Engineering, Hyderabad, A.P, INDIA \\ ${ }^{2}$ Department of Mechanical Engineering, JNTUJ College of Engineering, Jagityal, A.P, INDIA \\ ${ }^{3 *}$ Sri Sai College of Engineering and Technology, Loluru(V), Anantapur(Dist.), A.P, INDIA \\ "Corresponding Author: e-mail: kalyaniradha@gmail.com, Tel +91-9440517729
}

\begin{abstract}
The major problem with the direct use of vegetable oils as fuel into CI engines is their higher viscosity. It interferes the fuel injection and atomization and contributes to incomplete combustion, nozzle clogging, excessive engine deposits, ring sticking, producing thick smoke, etc. The problem of higher viscosity of vegetable oils can be overcome to a greater extent by various techniques, such as heating of fuel lines, trans-esterification, modification of injection system, etc. In the present investigation, short term tests were conducted with the use of untreated cotton seed oil in a single cylinder, four stroke, and direct injection diesel engine. Tests were conducted with cotton seed oil and diesel. To improve the combustion characteristics of cotton seed oil in an unmodified engine, effect of increase in injection pressure was studied. The injection pressure was increased from 180 bar to 240 bar (in steps of 15 bar). The investigation revealed that the optimum pressure for cottonseed oil as 210 bar and comparison of the performance of the engine was studied in terms of brake specific fuel consumption, brake thermal efficiency, indicated thermal efficiency, mechanical efficiency and exhaust emissions.
\end{abstract}

Keywords: Cotton seed oil; CI Engine; Injection pressure; performance characteristics; alternate fuels

\section{Introduction}

The physical, combustion and auto ignition properties of vegetable oils are almost similar to those of diesel fuels and hence can be used in diesel engines with little or no engine modifications. However, high viscosity and low volatility being inherent properties of most of such vegetable oils produced from plants (seeds), constraining their direct use in engines without any modifications. High viscosity interferes with fuel jet penetration, atomization and produces thick smoke in the exhaust. Therefore, the vegetable oils are not ideally suited as fuels for diesel engines; they are to be modified to bring closer to diesel oil in their properties.

Investigations have been carried out on a variety of vegetable oils like jatropa oil, karanj oil, rice bran oil, rapeseed oil etc in diesel engines. Diesel engines with vegetable oils as fuels produce the same power output but reduced thermal efficiency and increased emissions. The particulate emissions of vegetable oils are higher than that of diesel fuel with lower value of $\mathrm{NO}_{\mathrm{x}}$ emissions. However, their performance is slightly inferior to diesel (Agnes et al., 2007; Raja et al., 2003; Jeffrey and Nancy, 2009). Investigations were carried out to study the effects of vegetable oil fuels and their methyl esters (raw sunflower oil, raw cottonseed oil, raw soybean oil and their methyl esters, refined corn oil and refined rapeseed oil) on a direct injection, four stroke and single cylinder diesel engine (Altin et al., 2001). They concluded that raw vegetable oils can be used as fuel in diesel engines with some modifications and when compared to diesel fuel, a little amount of loss in power was observed and the particulate emissions were higher than that of diesel fuel. Vegetable oil methyl esters exhibited the performance and emission characteristics closer to the diesel fuel. The physical, chemical and fuel related properties of tobacco seed oil were investigated and suggested that this non edible oil may be an appropriate substitute for diesel fuel. Investigations on tobacco seed oil suggested that this non edible oil may be an appropriate substitute for diesel fuel (Giannelos et al., 2002). 
The use of vegetable oils in diesel engines was studied by Nazar et al. (2004). Experiments were conducted to access the suitability of karanj and coconut oils as fuels in a diesel engine, and concluded that, for short term tests coconut oil and karanj oil can be directly used in diesel engines without any engine modifications. Almost same power output was noticed with slightly reduced thermal efficiency with coconut oil and karanj oil when compared with diesel. Both HC and CO emissions were found high for vegetable oils under normal operating conditions.

Review on the use of vegetable oils as fuels for internal combustion engines was conducted (Bhattacharyya and Reddy, 1994). They reported that the major difference between diesel fuel and vegetable oil included, for the later, the significantly higher viscosities and moderately higher densities, lower heating values, rise in the stoichiometric fuel/air ratio due to the presence of molecular oxygen and the possibility of thermal cracking at the temperatures encountered by the fuel spray in the naturally aspirated diesel engines. These differences contribute to the poor atomization, coking tendencies, carbon deposition and wear that generally experienced and which adversely affect the durability of the engine. Injection timing and proper ratio of vegetable oil and diesel in the blend were found to be critical in determining the proper atomization. The gathered information indicates a better performance of sunflower, soybean and rapeseed oil relative to the other oils, both in terms of durability and thermal efficiency and power output.

Effect of injection pressure has been investigated to use Jatropa Curcas oil in diesel engine and observed that there was a slight improvement in the performance of engine with increase in injection pressure (Srinivasa et al., 1997). The production of biodiesel by two-step esterification was done using rubber seed oil with acid catalyst (Ramadhas et al., 2005). Transesterification with methanol and characterization of vegetable oils and their methyl ester as the substitute of the petroleum fuel and future possibilities of Biodiesel production were reviewed (Singh and Singh, 2010). Methanol along with jatropa oil was used in a CI engine in dual fuel mode operation. Methanol was carbureted with different jet openings and was observed that rate of pressure rise and peak pressures were high with jatropa oil operation. However, with the methanol induction in the dual fuel mode, the rate of pressure rise and peak pressure was reduced considerably. The effect of supercharging on the performance of diesel engine with cotton seed oil was studied (Amba and Rama, 2003). The performance improved with increase in $\mathrm{NO}_{\mathrm{x}}$ emissions. The experiment that for biodiesel mixtures, CO emission was lower than that of diesel fuel (Nabi et al., 2008). Compare to neat diesel fuel, 30\% biodiesel mixtures reduced CO emissions by $24 \%$. CO emitted by all biodiesel blends is lower than the ones for the corresponding diesel fuel case. This reduction in CO increases as the percentage of biodiesel in the blend increases (Rakopoulos et al., 2008, Gattamaneni et al., 2008; Ghobadian et al., 2009). When biodiesel is used as fuel at all loads there was a reduction in CO emission (Usta et al., 2005). At low concentration of the biodiesel in the blend, the inbuilt oxygen helps in complete combustion of the fuel. But high concentration of biodiesel increases the viscosity of the fuel and there is a slight increase in the specific gravity. This causes poor atomization of biodiesel which results in poor combustion of fuel; suppresses the complete combustion process and as a result the emission of CO increases (Makareviciene et al., 2003; Suresh et al., 2008).

The effect of injector opening pressure on the performance of a jatropha oil fuelled compression ignition engine, the optimum injection opening pressure was found out for jatropha oil and comparison of performance, emissions and combustion parameters were made with diesel (Narayana and Ramesh, 2004). Increasing the injection pressure lead to a significant reduction in smoke level, HC emissions and also improved the brake thermal efficiency.

Experimental investigations were carried out varying different parameters to optimize the production of biodiesel using methanol as catalyst (Siva et al., 2009). The optimum conditions for biodiesel production are suggested i.e. a maximum of $76 \%$ biodiesel was produced with $20 \%$ methanol in presence of $0.5 \%$ sodium methaoxide. Thermal efficiency with biodiesel mixtures was slightly lower than that of neat diesel with reduced CO, PM, smoke emissions. While 10\% BD mixtures reduced PM, smoke emission by $24 \%$ and $14 \%$ respectively. With $30 \%$ biodiesel blend, they observed reduction in CO emission by $24 \%$ and $10 \%$ increase in the NOx emission duel to the presence of oxygen in their molecular structure.

Experimental studies were carried out on the performance of castor non-edible vegetable oil and its blends with diesel on a single cylinder, 4 stroke, naturally aspirated, direct injection, water cooled, eddy current dynamometer Kirloskar Diesel Engine at 1500 rpm for variable loads (Naga et al., 2009). It is observed that $25 \%$ of neat Castor oil mixed with $75 \%$ of diesel is the best suited blend for Diesel engine without heating and without any engine modifications. The Brake Thermal Efficiency, BSFC of castor oil are $33.45 \%$ lower and 54.76\% higher, while CO, UHC, smoke are 56.41\%, 20.27\%,31.32\% respectively higher and NOx are $44 \%$ lower compared to those of diesel. This is due to incomplete combustion of the fuel and delay in the ignition process.

As an effective solution for improving performance and emission characteristics of CSO biodiesel blends with petrodiesel, coating of combustion chamber parts such as surfaces of cylinder, head, piston, inlet and exhaust valves with a ceramic material was introduced in single cylinder DI CI engine and the performance such as engine power and SFC; emission values such as CO and smoke of the CSO blends with diesel (B20 and B40) were improved (Hazar, 2010). The study for the effect of preheated CSO biodiesel on performance and exhaust emission of CI engine (Karabektas et al. 2008) and reported that optimum preheating temperature of CSO biodiesel was $90{ }^{\circ} \mathrm{C}$ due to favorable effects on BTE and CO emissions. However, this biodiesel caused higher NOx emissions. The studies related to neat CSO and diesel fuel blends were conducted by (Fontaras et al., 2007) a common rail Euro 3 compliant diesel engine was tested with CSO blends. They concluded that $10 \%$ CSO and $90 \%$ diesel blends can be applied in common rail diesel engine without impacts on operation and emission seven though proper idle engine management is required. However, the engine suffered from misfuelling at low ambient temperatures (Fontaras et al., 2007). In addition, NOx appear to increase slightly in some cases. 
Different parameters for the optimization of biodiesel production were investigated and suggested that a maximum of $77 \%$ biodiesel was produced with $20 \%$ methanol in presence of $0.5 \%$ sodium hydroxide. The engine experimental results showed that exhaust emissions including carbon monoxide (CO) particulate matter (PM) and smoke emissions were reduced for all biodiesel mixtures, but a slight increase in oxides of nitrogen (NOx) emission was experienced for biodiesel mixtures (Nurun et al., 2009). The application methods of jatropha oil as a substitute for CI engine gave the lower brake thermal efficiency and higher specific fuel consumption compared to diesel fuel operation and compared with seven different oils. It was reported that a diesel engine without any modification would run successfully on a blend of $20 \%$ vegetable oil and $80 \%$ diesel fuel without damage to engine parts (No, 2010). Dual fuel mode operation using coir-pith derived producer gas and rubber seed oil as pilot fuel was analyzed for various producer gas-air flow ratios and at different load conditions and observed that specific energy consumption was high along with exhaust emissions and it suitable for stationary engine application, particularly power generation (Ramadhas et al., 2008).

It is required to conduct the research about the exhaust emission characteristics of LSO biodiesel blends in diesel engine. In the test of single cylinder, DI CI engine that has a rated output of $4.4 \mathrm{~kW}$ at $1500 \mathrm{rpm}$, the experimental results showed that the optimum fuel injection pressure was 24MPa with LO biodiesel (Puhan et al., 2009). At this optimum pressure, the thermal efficiency was similar to diesel and a reduction in CO, HC and PM with an increase in NOx was noticed. The combustion analysis showed that the ignition delay was lower at higher injection pressures compared to diesel. Performance studies were carried on cottonseed oil and diesel blends and observed that, there was about 3.7\% decrease in BSFC, 6.7\% increase in mechanical efficiency, $1.7 \%$ increase in brake thermal efficiency, and $21.7 \%$ decrease in smoke density with CSO10D90 blend as compared to that of neat diesel operation, and performance of other blends and straight vegetable CSO was inferior to conventional diesel (Murali and Mallikarjuna, 2009).

Keeping the above points in view, a study was undertaken to investigate the performance characteristics of cotton seed oil and diesel fuel at different injection pressures without any major engine modifications on the engine.

\section{Experimental Setup}

A single cylinder direct injection type, 4 stroke, water cooled vertical diesel engine developing $3.5 \mathrm{~kW}$ at $1500 \mathrm{rpm}$ is coupled with rope brake dynamometer for experimentation purpose. The dynamometer consists of a pulley coupled to the engine as shown in Figure 1. A thick rope is wound around the pulley. One end of the pulley is connected to lead screw that can be rotated by wheel mounted on it and other end is connected to a spring balance. Load can be applied by rotating the wheel. As the rope is tightened around the pulley, engine is loaded and the spring balance shows the load in $\mathrm{kg}$. Control panel consists of engine speed indicator which indicates the speed of engine in RPM. Fuel consumption was measured by a glass burette mounted on the control panel. Exhaust emissions and smoke were measured with 2- Gas Analyser model EGA 1000/2 and Diesel Smoke Meter model DSM 2000. The different physical properties of cotton seed oil, procured for the purpose of experimentation were determined in the laboratory. Specific gravity and gross calorific values are determined with hydrometer and Bomb calorimeter respectively.

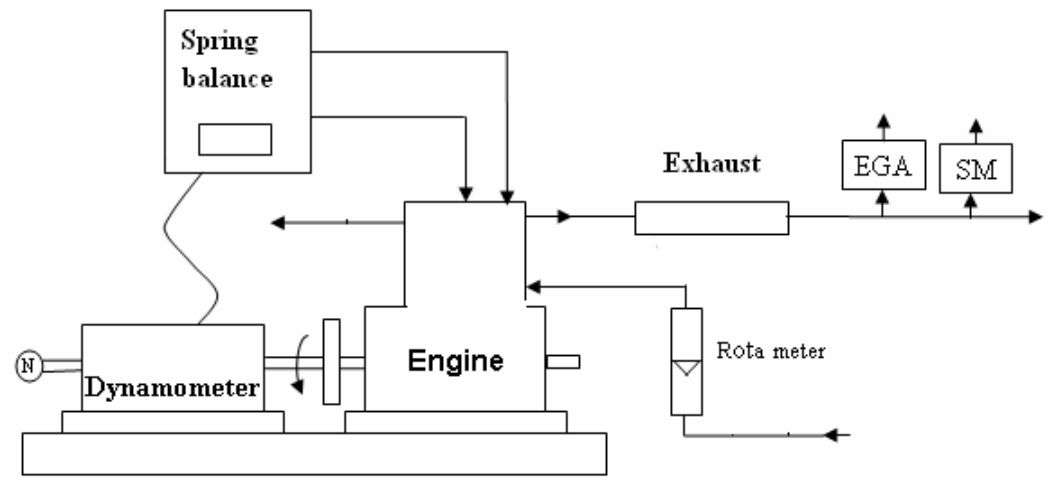

Figure 1: Experimental set up

2.1 Experimentation: Experiments were conducted with diesel and cotton seed oil under naturally aspirated conditions with increased injection pressures from 180 bar to 240 bar (in steps of 15 bar). Table 1 and Table 2 show the specifications of the engine and the properties of the fuels respectively. 
Table 1: Specifications of the engine:

\begin{tabular}{|c|c|c|}
\hline Type & \multicolumn{2}{|l|}{ Dimensions } \\
\hline Make & \multicolumn{2}{|l|}{ Komet } \\
\hline Type & \multirow{2}{*}{\multicolumn{2}{|c|}{$\begin{array}{l}\text { Single cylinder, Four stroke, Vertical Diesel engine 5H.P. } \\
(3.5 \mathrm{~kW} \text { ) at } 1500 \mathrm{rpm} \\
\text { rope brake }\end{array}$}} \\
\hline Dynamometer & & \\
\hline Cooling & \multicolumn{2}{|l|}{ Water cooling } \\
\hline Charging & \multicolumn{2}{|l|}{ Naturally aspirated } \\
\hline Bore & \multicolumn{2}{|c|}{$80 \mathrm{~mm}$} \\
\hline Stroke & \multicolumn{2}{|l|}{$110 \mathrm{~mm}$} \\
\hline Diameter of pulley & \multicolumn{2}{|l|}{$360 \mathrm{~mm}$} \\
\hline \multicolumn{3}{|c|}{ Table 2: Properties of Fuels } \\
\hline Property & Diesel & Cotton seed oil \\
\hline Density $\left(\mathrm{kg} / \mathrm{m}^{3}\right)$ & 850 & 912 \\
\hline Calorific Value (kJ/kg) & 43400 & 39500 \\
\hline Kinematic Viscosity (cSt @40ㄷ) & 3.5 & 55.6 \\
\hline Flash Point $\left({ }^{\circ} \mathrm{C}\right)$ & 68 & 205 \\
\hline Fire Point $\left({ }^{\circ} \mathrm{C}\right)$ & 107 & 228 \\
\hline
\end{tabular}

\section{Results and Discussion}

Initially the engine was run with diesel to know the performance at 180 bar injection pressure as specified by the manufacturer specified and the injection pressures were increased from 180 bar to 240 bar (in steps of 15 bar). Further experiments were conducted with cotton seed oil and diesel. The performance of the engine with different blends of cotton seed oil and diesel at different injection pressures was studied.

3.1 Brake Specific Fuel Consumption: From Figure 2 it may be observed that as the load on the engine increases brake specific fuel consumption decreases. The injector was set for different opening pressures namely 195 bar, 210 bar, 225 bar and 240 bar and the engine was tested. A glance on the figure reveals that BSFC decreases with increase in brake power. This may be due to good atomization at higher injection pressure which helps in faster rate of heat release.

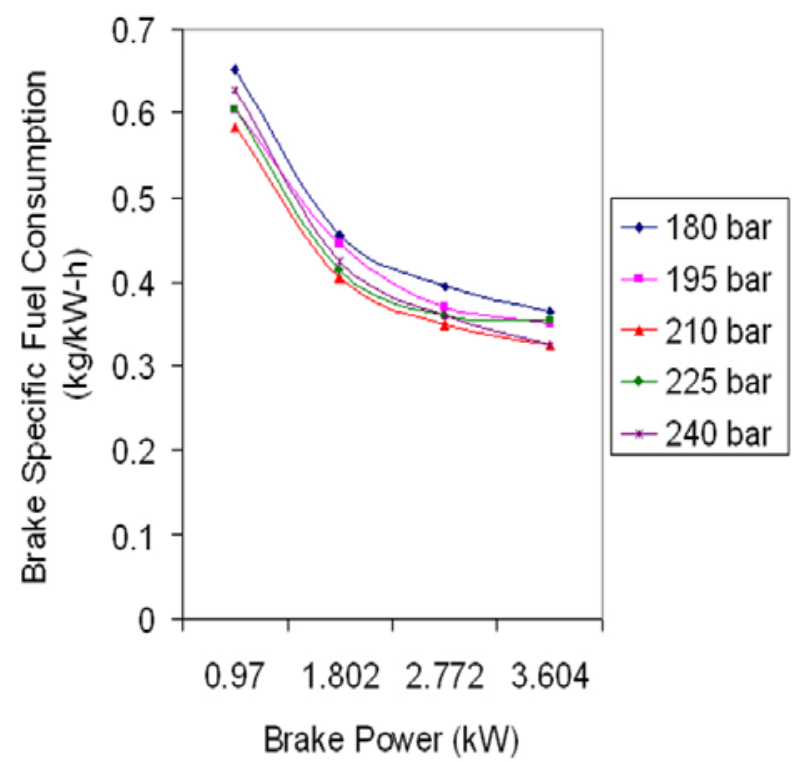

Figure 2: BSFC vs. BP 
3.2 Brake Thermal Efficiency: From Figure 3 the brake thermal efficiency is observed to be highest at 210 bar injection pressure. Increasing the injection pressure leads to better spray atomization particularly at the beginning and end of injection. Since injection always takes place at high pressures; when the injection opening pressure is raised, the atomization is better. This leads to better performance. Between 210 and 225 bar there seems to be no significant difference. The highest pressure of 240 bar deteriorates the performance, probably due to reasons

1. Improper combustion.

2. Very fine droplets of fuel have less momentum.

The brake thermal efficiency increases from $25.01 \%$ to $28.02 \%$ when the injection pressure is raised from 180 bar to 210 bar at full load. The increase in the brake thermal efficiency also means that less fuel is injected for the same output.

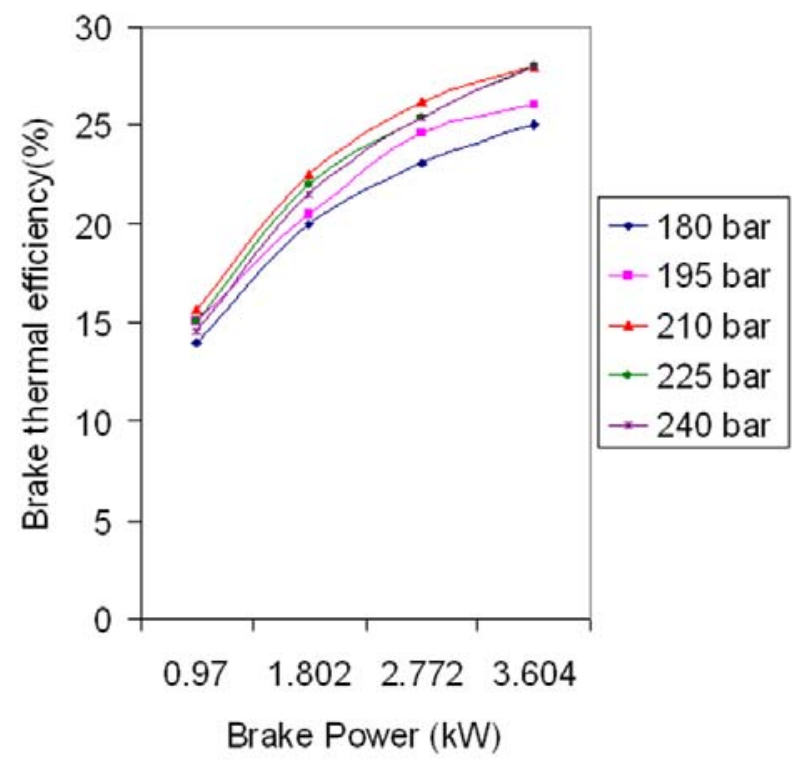

Figure 3: Brake thermal efficiency vs. BP

3.3 Unburnt Hydrocarbons: The level of unburnt hydrocarbon emissions is shown in Figure 4. As the opening pressure increases the HC emissions are reducing because, higher injection opening pressures will lead to a proper spray while the injection starts. This will enhance the performance with vegetable oils as they have a high viscosity. This is probably because of the improvement in the spray, which can lead to a lower physical delay. The improved spray also leads to better combustion and thermal efficiency.

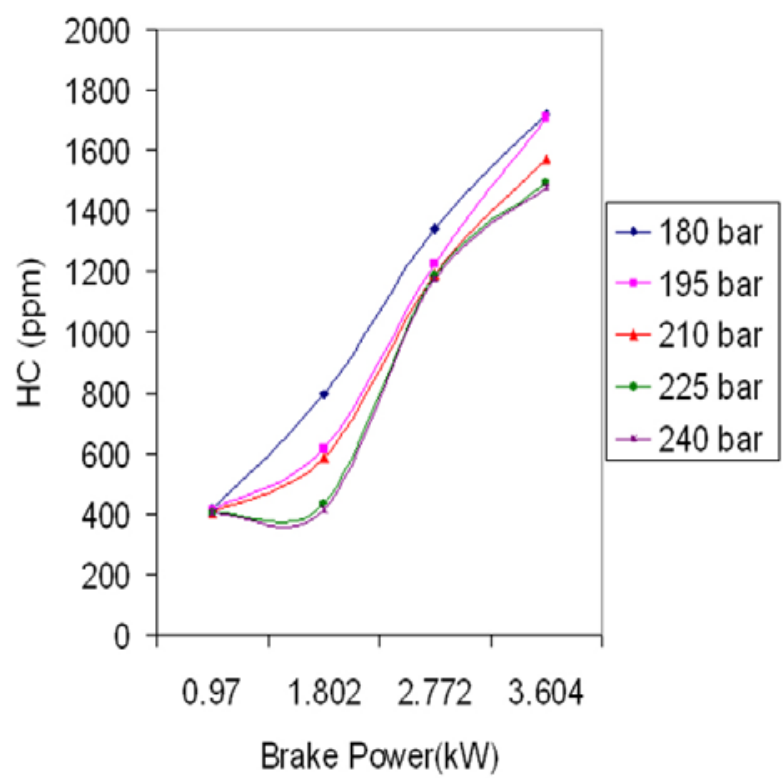

Figure 4: HC emissions vs. BP 
3.4 Smoke Levels: From Figure 5 it can be concluded that the smoke level decreases with increasing the injector opening pressure due to better atomization of fuel due to rise in the injection pressure leading to better combustion.

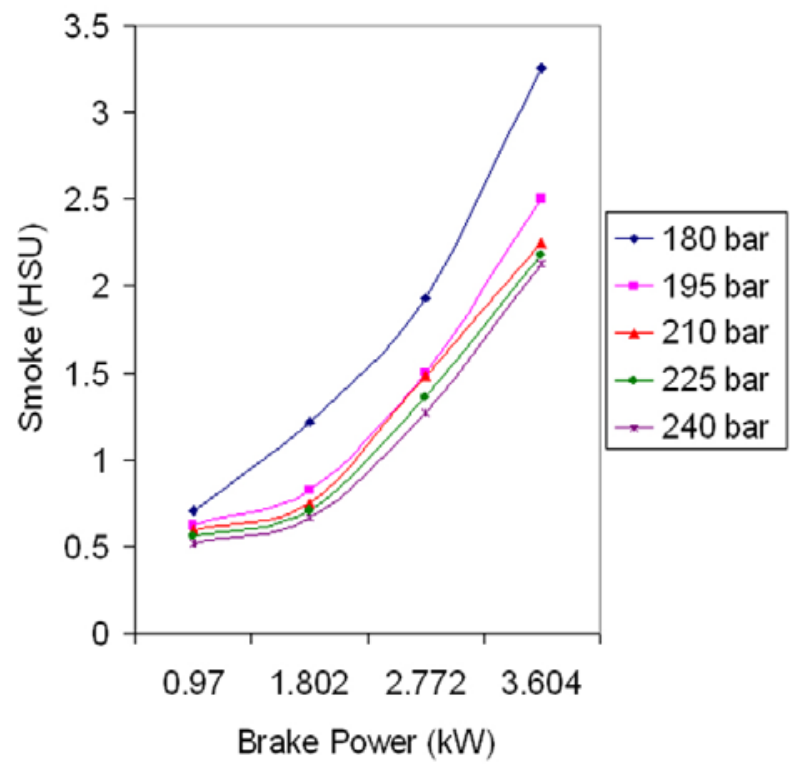

Figure 5: Smoke vs. BP

\section{Conclusions}

The following conclusions are drawn based on the experimental work. Increased injection pressure has a significant effect on enhancing engine performance and lowering emissions. Increase in the injection pressure from 180 bar to 240 bar with cotton seed oil as fuel lead to:

1. Quieter operation of the engine is observed when cotton seed oil is used as fuel.

2. Performance of engine with cotton seed oil as fuel is better at an IP of 210 bar.

3. An increase in the Brake thermal efficiency from $25.02 \%$ to $28.02 \%$ was observed with increase in injection pressure from 180bar to 210 bar; due to better atomization and improved combustion of the fuel.

4. Lowering of the HC emissions from $1720 \mathrm{ppm}$ to $1480 \mathrm{ppm}$.

5. Performance of engine with cotton seed oil as fuel at an IP of 210 bar is approximately similar to the operation of engine with diesel.

In the present investigation, short term tests were conducted with the use of untreated cotton seed oil in a single cylinder, four stroke, and direct injection diesel engine. To improve the combustion characteristics of cotton seed oil in an unmodified engine, effect of increase in injection pressure was studied. The injection pressure was increased from 180 bar to 240 bar (in steps of 15 bar) which is limited to a certain extent.

Future work may be extended to:

- 1000 hrs durability tests may be conducted on diesel engines and the wear associated with the engine moving parts may be analyzed

- Increase in injection pressures in steps of 5 bar may be attempted

- Instead of modifying the existing engine, new designs of engines may be attempted keeping in mind comprehensive combustion optimization

- The studies on future biodiesel and biodiesel - diesel blends fuels may be carried out in order to reduce the viscosity of non-edible vegetable oils

\section{Nomenclature}

BSFC Brake specific fuel consumption, $\mathrm{kg} / \mathrm{kWh}$

BP Brake power $(\mathrm{kW})$

HC Hydrocarbon emissions (ppm)

HSU Hatridge smoke unit (HSU) 
IP Injection pressure (bar)

RPM Revolutions per minute (rpm)

\section{References}

Altin R., Cetinkaya S. and Yucesu H.S., 2001. The potential of using vegetable oil fuels as fuel for diesel engines, Energy Conversion and Management, Vol. 42, pp. 529 - 538.

Amba P.R.G. and Rama M.P., 2003. Effect of Supercharging on performance of DI Diesel engine with cotton seed oil, Energy Conversion and Management, 44, pp. 937 - 944.

Bhattacharya .S and Reddy C.S, 1994. Vegetable oils as Fuel for Internal combustion Engines: A Review, Journal of Agricultural Engineering Research. 57, pp. 157-166.

Fontaras G, Tzamkiozis T, Hatziemmanouil E, Samaras Z., 2007. Experimental study on the potential application of cotton seed oil-diesel blends as fuels for automotive diesel engines, Trans I Chem E Part B Process Safety Environ Protect, 85(B5),pp. 396403.

Fontaras G, Samaras Z, Miltsios G, 2007. Experimental evaluation of cottonseed oil- diesel blends as automotive fuels via vehicle and engine measurements. SAE paper,No. 2007-24-0126.

Gattamaneni LNR, Subramani S, Santhanam S and Kuderu R, 2008. Combustion and emission characteristics of diesel engine fuelled with rice bran oil methyl ester and its diesel blends, Thermal Science, 12(1), pp. 139-150.

Ghobadian B, Rahimi H, Nikbakht AM, Najafi G and Yusaf TF, 2009. Diesel engine performance and exhaust emission analysis using waste cooking biodiesel fuel with an artificial neural network, Renewable Energy, 34, pp. 976-982.

Giannelos P.N., Zannikos F., Stournas S., Lois E., Anastopoulos G., 2002, Tobacco seed oil as an alternative diesel fuel: physical and chemical properties, Industrial Crops and Products, 16, pp. 1-9.

Hazar H., 2010. Cotton methyl ester usage in a diesel engine equipped with insulated combustion chamber, Applied Energy, 87, pp. 134-40.

Jeffrey SG and Nancy AM, 2009. The impacts of combustion emissions on air quality and climate-From coal to biofuels and beyond, Atm. Environment, 43, pp. 23-36.

Karabektas M, Ergen G, Hosoz M. 2008. The effects of preheated cotton seed oil methyl ester on the performance and exhaust emissions of a diesel engine, Applied Thermal Engineering, 28, pp. 2136-43.

Nabi N, Rahman M and Akhter S, 2009. Biodiesel from cotton seed oil and its effect on engine performance and exhaust emissions, Applied Thermal Engineering, 29 (11-12), pp 2265-2270.

Naga P. Ch. S, Vijaya K.R.K, Kumar B.S.P., Ramjee.E, Hebbel O.D. and Nivendgi M.C., October 2009. Performance and emission characteristics of a diesel engine with castor oil, Indian Journal of Science and Technology, 2 (No.10), pp.25-31.

Narayana R.J. and Ramesh A., 2004. Effect of injector opening pressure on the performance of a Jatropa oil fueled Compression Ignition Engine, National Conference on State of the art of technologies in Mechanical Engineering, NCSAME- 2004.

Nazar .J, Sandesh G., Ramesh A. and Nagalingam B., Use of Vegetable Oils in Diesel Engines, National conference on State of the art of technologies in Mechanical Engineering, NCSAME- 2004.

No S.-Y., 2010. Inedible vegetable oils and their derivatives for alternative diesel fuels in CI engines: A review, Renewable and Sustainable Energy Reviews, (InPress)

Nurun N. Md., Mustafizur R. Md., Shamim A. Md., 2009. Biodiesel from cotton seed oil and its effect on engine performance and exhaust emissions, Applied Thermal Engineering. 29, pp. 2265-2270

Oman H, 2003. Energy sources for the worlds post petroleum era, IEEE Aerospace Elec. Sys. Vol. 18, pp. 35-39.

Puhan S, Jegan R, Balasubbramanian K, Nagarajan G, 2009. Effect of injection pressure on performance, emission and combustion characteristics of high linolenic linseed oil methyl ester in a DI diesel engine, Renewable Energy, Vol. 34, pp.1227-33.

Raja A, Sarvanan B, Sitharthaseelan J, Sudhkar S and Sarvanan GS, 2003. Fumigation of methanol in diesel engine through recovering waste heat from exhaust gas with fuel additives, Institute of Engineers (I) Journal, Vol. 83, pp. 153-157.

Ramadhas A.S, Jayaraj S., Muraleedharan C., 2005. Biodiesel production from high FFA rubber seed oil, Fuel, 84, pp. 335-340

Ramadhas A.S, Jayaraj S., Muraleedharan C., 2008. Dual fuel mode operation in diesel engines using renewable fuels: Rubber seed oil and coir-pith producer gas, Renewable Energy, 33, pp. 2077-2083

Rakopoulos C.D., Rakopoulos D.C., Hountalas D.T., Giakoumis E.G. and Andritsakis E.C., 2008. Performance and emissions of bus engine using blends of diesel fuel with biodiesel of sunflower or cottonseed oils derived from Greek feedstock, Fuel, Vol. 87, No. 2, pp. 147-157.

Shameer B..M, Krishna R.B.G., Vijaya Kumar R.K., Ravi Kumar .P and Sudheer Prem Kumar.B, July 2009. Performance analysis of a single cylinder diesel engine using cotton seed oil, International Journal of Applied Engineering Research (online).

Singh S.P. and Singh D., 2010. Biodiesel production through the use of different sources and characterization of oils and their esters as the substitute of diesel: A review, Renewable and Sustainable Energy Reviews, Vol. 14, pp. 200-216

Siva K.A, Maheswar D., Vijaya Kumar R. K., September 2009. Comparison of diesel engine performance and emissions from neat and transesterified cotton seed oil, Jordan Journal of Mechanical and Industrial Engineering, Vol. 3, No.3, pp. 190-197. 
Srinivasa R.S., Rama Mohan Rao P. and Sitharama Rao T.L, Janurary 1997. Jatropa oil as an alternate fuel for diesel engines, Proceedings of National Conference on Alternative \& Renewable Energy Technologies, pp. 10-11.

Suresh K.K, Velraj R and Ganesan R, 2008. Performance and exhaust emission characteristics of a CI engine fueled with Pongamia pinnata methyl ester (PPME) and its blends with diesel, Renewable Energy, Vol. 33, No. 10, pp. 2294-2302.

Usta N, 2005. An experimental study on performance and exhaust emissions of a diesel engine fuelled with tobacco seed oil methyl ester. Energy Conversion Management, Vol. 46, pp. 2373-2386.

\section{Biographical notes}

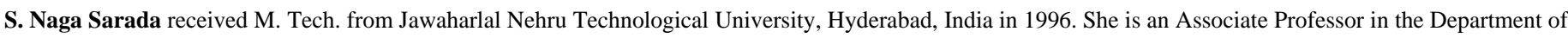
Mechanical Engineering, JNTUH College of Engineering, Hyderabad, Andhra Pradesh, India. She is having more than 13 years of experience in teaching and R

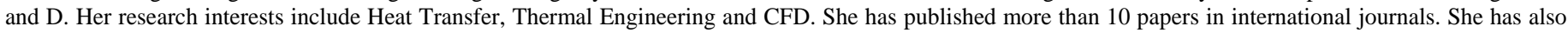
presented more than 10 research articles in national and international conferences. She is a Life member of ISHMT and ISTE.

M. Shailaja received M. Tech. from Jawaharlal Nehru Technological University, Hyderabad, India in 2005. She is an Assistant Professor in the Department of Mechanical Engineering, JNTUH College of Engineering, Hyderabad, Andhra Pradesh, India. She is having more than 8 years of experience in teaching and Research. Her research interests include IC Engines, Alternate fuels and Thermal Engineering. She has presented more than 5 research articles in national and international conferences.

Dr. A.V.Sita Rama Raju is a Professor in the Department of Mechanical Engineering, JNTUH College of Engineering, Hyderabad, Andhra Pradesh, India. He has more than 20 years of experience in teaching and research. His current area of research includes IC Engines, Thermal Engineering, Combustion modeling and Alternate fuels. He has published more than 22 papers in referred international journals. He has also presented more than 20 research articles in national and international conferences. He is member of ISTE, LMC, etc.

Dr. K. Kalyani Radha received M. Tech. and Ph.D from Jawaharlal Nehru Technological University, Hyderabad, India in 2004 and 2009 , respectively. She is presently working as a Principal, Sri Sai College of Engineering and Technology, Anantapur, Andhra Pradesh, India. She is having around 10 years of experience in teaching and Research. Her research interests include IC Engines, Combustion modeling, Alternate fuels, Heat transfer, Refrigeration and Air-conditioning. She has published more than 10 papers in International journals. She has also presented more than 10 research articles in National and International conferences. She is a Life member of LMC, ISHMT and ISTE.

Received June 2010

Accepted August 2010

Final acceptance in revised form October 2010 